\title{
Effects of ad-valorem taxes on location decision under free entry Cournot oligopoly
}

\author{
Yeung-Nan Shieh* \\ Department of Economics, San Jose State University, USA
}

Received: 18 July 2012

Revised: 28 December 2012

Accepted: 8 January 2013

\begin{abstract}
This paper examines the impact of the ad-valorem commodity tax as a policy device on the location decision of undifferentiated oligopolistic firms with free entry. It shows that: (1) When the distance between the plant location and the output market is held constant, the optimum location for the oligopolistic firm would be independent of the ad-valorem tax if the production function is homothetic, and (2) when the distance between the plant location and the output market is a decision variable, the optimum location for the oligopolistic firm will move closer to the output market if the demand function is linear or concave. These results are significantly different from the conventional results based on the monopolistic location model. It indicates that the effect of an ad-valorem tax on the location decision of oligopolistic firms crucially depend upon the shape of market demand function.
\end{abstract}

Keywords: ad-valorem commodity tax, undifferentiated oligopoly, location decision, Weber-Moses triangle

JEL Classification Codes: H25, L13, R38

\section{Introduction}

Since the pioneering work of Moses (1958), a large number of studies have attempted to integrate location theory with neoclassical production theory. Most of location literature examines the impact of the characteristics of production function on the plant location decision (see Martinich and Hurter, 1990). One of important assumptions is that business taxes are insignificant and negligible. However, it is well-known that local government often uses different types of taxes to persuade certain kinds of industry to locate in its region or to dissuade other forms of industry from locating there. This indicates that business taxes have a significant impact on the firm's location decision. In an interesting and important paper, Hwang and Mai (henceforth HM) (1987) incorporated the ad-valorem commodity tax into the linear location model and examined the impact of an ad-valorem tax on the plant location

\footnotetext{
*E-mail: ynshieh@yahoo.com.

Citation: Shieh, Y-N (2013) Effects of ad-valorem taxes on location decision under free entry Cournot oligopoly, Economics and Business Letters, 2(1), 5-12.
} 
decision. Chan and Shieh (henceforth CS) (1997) extended Hwang and Mai's analysis to the two-dimensional Weber-Moses triangular location model. Assuming that (1) a monopolist uses two transportable inputs located at two vertices to produce a product which is sold at CBD (i.e., Central Business District) located at the third vertex and (2) the objective of the firm is to find the profit maximizing plant location within the triangle, they obtained the following interesting propositions.

CS1. When the distance of plant location from CBD is held constant, the optimum location is independent of the change of an ad-valorem tax if and only if the production function is homothetic. Chan and Shieh (1997, p. 541).

CS2. When the distance of plant location from CBD is a decision variable, the optimum location is independent of the change of an ad-valorem tax if and only if the production function exhibits constant returns to scale. It moves toward CBD as the ad-valorem tax increases if and only if the production function exhibits decreasing returns to scale, and away from CBD if and only if the production function exhibits increasing returns to scale. Chan and Shieh (1997, p. 543).

These results are based on the polar case of monopoly. They show that the impact of an advalorem tax on the location decision of a firm crucially depends upon the economic scale of production function and the demand factors of location are not significant. Given that oligopolistic industries are relatively common in the economy, it is surprising that the impact of an ad-valorem tax in the oligopolistic location model has received little attention.

The purpose of this paper is to explicitly incorporate the ad-valorem taxes into Mai and Hwang (1992) two-dimensional oligopoly triangular location model and examine the impact of a change in the ad-valorem tax on the plant location of undifferentiated oligopolistic firms. ${ }^{1}$ This Weber-Moses triangular location model has been widely used in location theory, as Hurter and Martinich pointed out (1989), because of greater tractability. In a recent paper, Chen and Shieh (2011) introduced the specific commodity tax into Mai and Hwang (1992) model. They showed that when plant location is a decision variable the effects of a change in the specific tax on output per firm, the number of firms and total output will be different from the well-known Besley (1989) results in non-spatial setting. However, they did not consider the case of an ad-valorem tax. In this paper, we will show that the impact of an ad-valorem tax on the location decision of undifferentiated oligopolistic firms crucially depends upon the shape of inverse demand curve, and CS1holds but CS2 may not hold in the oligopolistic location model.

\section{An oligopolistic location model}

Following Mai and Hwang (1992), our analysis is based on the following assumptions.

(a) $N$ firms employ two transportable inputs $\left(m_{1}\right.$ and $\left.m_{2}\right)$ located at A and B to produce a homogenous product $(q)$ which is sold at the output market $C$ locating at the CBD. The location triangle in Figure 1 illustrates the location problem of oligopolistic firms. In figure 1, the distance $a$ and $b$ and the angle $\gamma$ are known; $h$ is the distance between the plant location $(E)$ and the $\mathrm{CBD}(C) ; z_{1}$ and $z_{2}$ are the distances of plant location $(E)$ from $A$ and $B$, respectively; $\theta$ is the angle between $\mathrm{CA}$ and $\mathrm{CE}$.

\footnotetext{
${ }^{1}$ Mai and Hwang model (1992) has served as a basis for a recent attempt to integrate location issues with trade policy, external economies of scale, oligopsony power in the input markets and specific commodity taxes, see Hwang and Mai (1999), Mai and Hwang (1997), Hwang and Shieh (2007), and Chen and Shieh (2011).
} 
Figure 1. The Weber-Moses Triangle

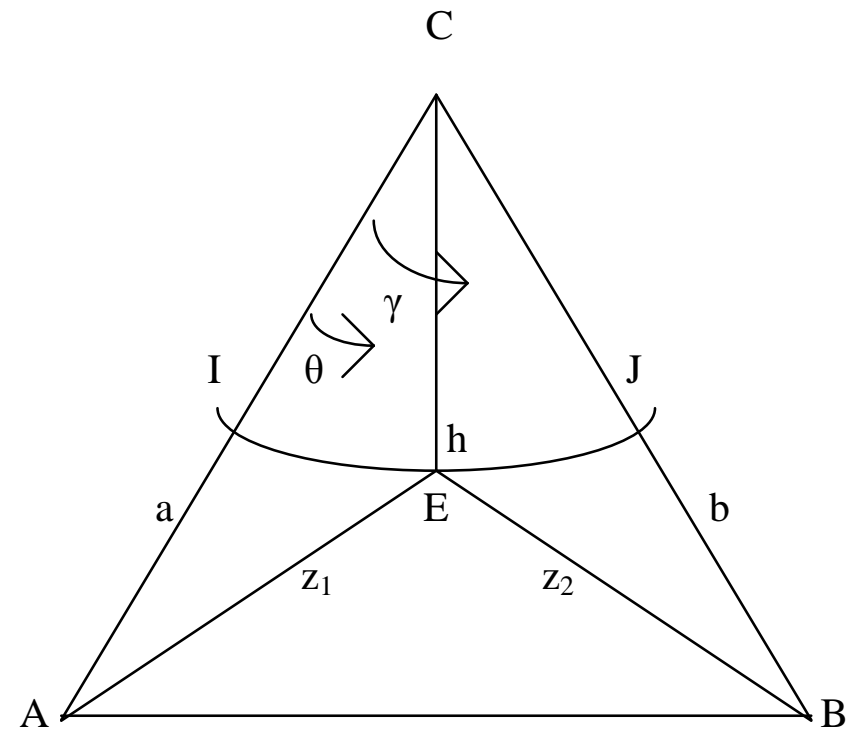

(b) Firms make Cournot-Nash conjectures about their rivals' production and location decisions and enter the industry without any restrictions until there is no economic profit. Assume also that equilibra are symmetric. Thus, we can neglect the location dispersion of firms and focus on the impact of market demand on the location decision of a representative firm.

(c) The production function is homothetic and can be specified as:

$$
q=f\left(m_{1}, m_{2}\right)
$$

with $f_{m 1} \equiv \partial q / \partial m_{1}>0, f_{m 2} \equiv \partial q / \partial m_{2}>0, f_{m 1 m 1} \equiv \partial^{2} q / \partial m_{1}^{2}<0$, and $f_{m 2 m 2} \equiv \partial^{2} q / \partial m_{2}^{2}<0$.

(d) The industry inverse demand function for output is given by

$$
P=P(Q)
$$

where $Q=\sum q^{i}$ is the market quantity demanded, $P_{Q} \equiv \partial P / \partial Q<0$, cf. Mai and Hwang (1992, p. 256).

It should be noted that $\sum$ denotes $\sum_{i=1}^{N}$.

(e) The prices of inputs and output are evaluated at the plant location $(E)$. The cost of purchasing inputs is the price of input at the source plus the freight cost, and the price of output is the market price minus the freight cost.

(f) Transportation rates per unit of output or inputs and per unit of distance are constant.

(g) The government imposes an ad-valorem commodity tax which can be specified as:

$$
T=t P q
$$

where $t=$ the ad-valorem tax rate, $1>t>0 .^{2}$

\footnotetext{
${ }^{2}$ It should be noted that in the specific tax case $T=t q$ where $t=$ the specific tax rate.
} 
(h) The objective of each firm is to find the optimum location and production within the Weber triangle which maximizes the profit.

It is of interest to note that the inclusion of an ad-valorem commodity tax constitutes the only point of departure from the Mai and Hwang model.

With these assumptions, the profit maximizing location problem of the representative firm is given by:

$$
\max \Pi=[P(Q)-r h] f\left(m_{1}, m_{2}\right)-\left(w_{1}+r_{1} z_{1}\right) m_{1}-\left(w_{2}+r_{2} z_{2}\right) m_{2}-t P(Q) \mathrm{f}\left(m_{1}, m_{2}\right)
$$

where $z_{1}=\left(a^{2}+h^{2}-2 a h \cos \theta\right)^{1 / 2}, z_{2}=\left[b^{2}+h^{2}-2 b h \cos (\gamma \theta)\right]^{1 / 2} ; w_{1}$ and $w_{2}$ are the base prices of $m_{1}$ and $m_{2}$ at their sources $A$ and $B ; r, r_{1}$ and $r_{2}$ are constant transportation rates of $q, m_{1}$, $m_{2} ; z_{1}, z_{2}$, and $h$ are the distances from the plant location to the source location $A, B$ and the market location $C$. It is worth mentioning that $q, m_{1}, m_{2}, h$ and $\theta$ are choice variables and $a, b$, $t, \gamma, w_{1}, w_{2}, r, r_{1}, r_{2}$ are positive parameters.

Assuming that the oligopolistic firm treats $q$ instead of $m_{1}$ and $m_{2}$ as a decision variable, we first derive the production cost function which does not include the transport cost of output. The production cost minimization subject to a given output at a given location can be specified as:

$$
\min L=\left(w_{1}+r_{1} z_{1}\right) m_{1}+\left(w_{2}+r_{2} z_{2}\right) m_{2}+\lambda\left[q-f\left(m_{1}, m_{2}\right)\right]
$$

where $\lambda$ is the Lagrange multiplier; $q, h$ and $\theta$ are parameters. Utilizing the standard comparative static analysis and the envelope theorem, we can show that the production function is homothetic if and only if the cost function is separable in the sense that:

$$
C(q ; h, \theta)=c\left(w_{1}+r_{1} z_{1}, w_{2}+r_{2} z_{2}\right) H(q)
$$

where $c$ is a function of the delivered prices of $m_{1}$ and $m_{2}, H$ is a function of output. For a detailed discussion of this, see Takayama (1993, Proposition 3.5., pp. 147-148) and Silberberg (1978, Chapter 10, pp. 300-309). Hence, the average production cost and marginal cost can be written as:

$$
\begin{aligned}
& A C=C(q ; h, \theta) / q=c(.) H(q) / q \\
& M C=C_{q}=c(.) H_{q}
\end{aligned}
$$

where $C_{q} \equiv \partial(q ; h, \theta) / \partial q$ and $H_{q} \equiv \mathrm{d} H(q) / \mathrm{d} q$.

Following Hanoch (1975), from (7) and (8), we obtain the following relation:

$$
H(q) / q>(=)<H_{q}
$$

if the production function exhibits increasing (constant) or decreasing returns to scale.

Substituting the production cost function $C=C(q ; h, \theta)$ into (4), we obtain the profit as a function of $q, \theta$ and $h$. The first-order condition for a maximum would be:

$$
\begin{aligned}
& \partial \Pi / \partial q=(1-t)\left(P+P_{Q} q\right)-r h-c(.) H_{q}=0 \\
& \partial \Pi / \partial \theta=-c_{\theta} H(q)=0 \\
& \partial \Pi / \partial h=-r q-c_{h} H(q)=0
\end{aligned}
$$

where $c_{\theta} \equiv \partial c(.) / \partial \theta, c_{h} \equiv \partial c(.) / \partial h$. Assume that the second-order conditions are satisfied and the possibility of the corner solution is excluded; cf. Kusumoto (1986) and Mai and Hwang (1992). We can solve (10)-(12) for $q, \theta$ and $h$ when entry is prohibited.

If free entry is allowed, each firm in the industry earns only normal profit. The following condition must be satisfied. 


$$
\Pi=[P(N q)-r h] q-c(.) H(q)-t P(N q) q=0
$$

If there is an interior solution, we can solve equations (10) - (13) for $q, \theta, h$ and $N$ in terms of $t$ and $v=\left(a, b, \gamma, w_{1}, w_{2}, r_{1}, r_{2}, r\right)$, where $v$ is a vector of remaining parameters.

$$
q=q(t, v), \quad \theta=\theta(t, v), \quad h=h(t, v), \quad N=N(t, v)
$$

The expressions for the partial derivatives such as $\partial q / \partial t, \partial \theta / \partial t, \partial h / \partial t$ and $\partial N / \partial t$ can be obtained by applying the standard comparative static analyses. It is worth mentioning before concluding this section that the production function must exhibit increasing returns to scale for the first-order conditions to have a solution as in (14). To see this, we divide both sides of equation (13) by q and obtain:

$$
(1-t) P(N q)-r h=[c(.) H(q) / q]
$$

Substituting (15) into (10), we obtain:

$$
(1-t) P_{Q} q=c(.)\left[H_{q}(q)-H(q) / q\right]
$$

Since the left-hand side of (16) is negative, for the right-hand side of (16) to be negative, $\left[H_{q}(q)-H(q) / q\right]<0$, i.e., the production function must exhibit increasing returns to scale. This indicates that $H(q) / q>H_{q}(q)$, cf. Hwang, Mai and Shieh (2007). It simply implies that in equilibrium all firms produce on the downward sloping part of the average cost curve and do not minimize average cost under Cournot competition with free entry.

This completes our modeling of the basic framework for studying the effect of an advalorem tax on the oligopolistic firm's location decision.

\section{Effects of ad-valorem taxes on location decision}

We are now in a position to examine the effect of a change in the ad-valorem tax rate on the optimum location. Following CS (1997), we consider two cases: (1) h is given and $\theta$ is the decision variable; (2) both $\mathrm{h}$ and $\theta$ are decision variables.

\section{1. $h$ is given}

In this case, the firm will locate its plant along arc $I J$ and equation (12) can be dropped from the first-order conditions. Totally differentiating equations (10), (11) and (13) and applying Cramer's rule, we obtain the following results:

$$
\begin{aligned}
& (\partial \theta / \partial t)_{h}=0 \\
& (\partial q / \partial t)_{h}=\left(1 / J^{\prime}\right)(1-t) \Pi_{\theta \theta} q^{3}\left(P_{Q}^{2}-P P_{Q Q}\right) \\
& J^{\prime}=\left(\Pi_{q q} \Pi_{N}-\Pi_{q} \Pi_{q N}\right) \Pi_{\theta \theta}=(1-t)^{2} \Pi_{\theta \theta} q^{2} P_{Q}\left(\left(P_{Q}+q P_{Q Q}\right)+\left\{P_{Q}-[1 /(1-t)] c(.) H_{q q}\right\}\right)
\end{aligned}
$$

where $\Pi_{\theta \theta}<0$ and $J^{\prime}<0$ by the stability condition. Or assume that $\left(P_{Q}+q P_{Q Q}\right)<0$ and $P_{Q}-$ $[1 /(1-t)] c(.) H_{q q}<0$, (Seade 1980, p. 483) and $\Pi_{\theta \theta}<0$ (SOSC). ${ }^{3}$

From equation (17), we can conclude that:

Proposition 1. If $h$ is constant and greater than zero and $\theta$ is a decision variable, the optimum location is independent of the change in an ad-valorem tax if and only if the production function is homothetic.

\footnotetext{
${ }^{3}$ The detailed derivations of the mathematical argument in this paper are available on request from the author.
} 
In other words, if the expansion path in the input space is linear through the origin, a change in the ad-valorem tax will change $\mathrm{m}_{1}$ and $\mathrm{m}_{2}$ by the same proportionate amount. Two material pulls compensate each other; hence the plant location is invariant with respect to a change in the ad-valorem tax. This result is consistent with CS1. However, our result generalizes CS1 since we show that CS1 can be applied to undifferentiated oligopolistic firms with free entry.

From equation (18), we can see that if the market demand function is linear or concave, i.e., $P_{Q Q} \leq 0,(\partial q / \partial t)_{h}>0 .{ }^{4}$ In other words, an increase in the ad-valorem tax will increase output per firm. This result is similar to that in the traditional non-spatial setting, cf. Tanaka (1993, p. 45). However, this result is different from that in the monopolistic location model. It can be shown that an increase in the ad-valorem tax always decreases output of monopolistic firm.

\section{2. $h$ and $\theta$ are variables}

In this case, both $h$ and $\theta$ are decision variables. Totally differentiating equations (10) - (13) and applying Cramer's rule, we obtain the following results.

$$
\begin{aligned}
& (\partial \theta / \partial t)=\left(1 / D_{4}\right)(1-t) \Pi_{\theta h} q^{3}\left(P_{Q}{ }^{2}-P P_{Q Q}\right) c_{h}\left\{[H(q) / q]-H_{q}\right\} \\
& (\partial h / \partial t)=\left(-1 / D_{4}\right)(1-t) \Pi_{\theta \theta} q^{3}\left(P_{Q}-P P_{Q Q}\right) c_{h}\left\{[H(q) / q]-H_{q}\right\} \\
& (\partial q / \partial t)=\left(D_{2} / D_{4}\right)(1-t) q^{3}\left(P_{Q}^{2}-P P_{Q Q}\right)
\end{aligned}
$$

where $\Pi_{\theta h}=-c_{h \theta} H(q), \Pi_{\theta \theta}=-c_{\theta \theta} H(q), \Pi_{q q}=(N+1) P_{Q}+N P_{Q Q} q-c H_{q q}, \Pi_{q}=P_{Q} q(N-1), \Pi_{q h}$ $=c_{h}\left\{[H(q) / q]-H_{q q}\right\}, D_{2}=\Pi_{\theta \theta} \Pi_{h h}-\Pi_{\theta h}{ }^{2}$ and $D_{4}$ is the relevant Hessian determinant. It should be noted that $\Pi_{\theta \theta}<0, D_{2}>0$ and $D_{4}>0$ by the stability conditions, $c_{h}<0$ can be seen from equation (12) and $[H(q) / q]-H_{q}>0$ is due to increasing returns to scale.

It is clear that the signs of $(\partial \theta / \partial t),(\partial h / \partial t)$ and $(\partial q / \partial t)$ depend upon the shape of market demand function, i.e., $\left(P_{Q}{ }^{2}-P P_{Q Q}\right)$. From $(20)-(22)$, we can see that if the market demand function is linear or concave, i.e., $P_{Q Q} \leq 0,(\partial q / \partial t)>0,(\partial h / \partial t)<0 .^{5}$ Thus, we can conclude that:

Proposition 2. An increase in the ad-valorem tax will increase output per firm and move plant location closer to the CBD if the demand function is linear or concave.

The effect of an ad-valorem tax on the optimum output and location is, perhaps, surprising. According to Hwang and Mai (1987) and Chan and Shieh (1997), in the monopoly case with increasing returns to scale, an increase in the ad-valorem tax will decrease the monopolist's output level and induce the firm to move its plant location farther away from CBD. But the above result shows that HM's and CS's monopolistic results can not apply to the oligopoly case. The economic interpretation behind Proposition 2 is given as follows. An increase in the ad-valorem tax rate does not change the slope of the demand curve at any output level but will increase the output price in equilibrium for the firm to break even. In the case where the demand function is linear or concave (i.e., $P_{Q Q} \leq 0$ ), a higher output price decreases the absolute value of the slope of the demand curve and so the point of tangency between demand curve and average curve occurs at a larger output level for each firm. Since the production function exhibits increasing returns to scale, the quantity of inputs, $\mathrm{m}_{1}$ and $\mathrm{m}_{2}$, per unit of

\footnotetext{
${ }^{4}$ It should be noted that in the case of the specific tax $(\partial q / \partial t)_{h}>0$ if $P_{Q Q}<0$, i.e., the market demand function must be concave. See Chen and Shieh (2011, p. 30).

${ }^{5}$ In the case of the specific tax, it can be shown that $(\partial q / \partial t)>0,(\partial h / \partial t)<0$ if $P_{Q Q}<0$. If the market demand function is linear, $P_{Q Q}=0$, then $(\partial q / \partial t)=0,(\partial h / \partial t)=0$. For details, see Chen and Shieh $(2011$, pp. 32-33).
} 
output declines, then the resources pull decreases while the market pull increases. As a result, the optimum location moves towards the CBD.

\section{Concluding remarks}

We have presented a simple oligopolistic location model and examined the impact of an advalorem tax on the production and plant location decisions of undifferentiated oligopolistic firms. We show the impact of an ad-valorem tax on the optimum production and plant location of an oligopolistic firm depends upon the shape of demand function. These results are different from HM's and CS's results based on the monopolistic location model. HM (1987) and CS (1997) show that the impact of an ad-valorem tax on the location decision of a monopolistic firm depends on the characteristics of production function only and the demand function plays no role.

In the case where the distance between the plant location and the output market is given, we show that the optimum location of undifferentiated oligopolistic firms is independent of the ad-valorem tax if the production function is homothetic.

In the case where the distance between the plant location and the output market is a decision variable, we show that an increase in the ad-valorem tax will cause each firm's output to rise and move the plant location closer to the output market if the demand function is linear or concave.

Although our analysis is based on a simplified oligopolistic location model, it has shed some light on the output and location effects of the ad-valorem tax in an oligopolistic location setting. It shows that the market demand condition plays an important influence on the effects of an ad-valorem tax on output and location decisions. Our results are significantly different from the conventional results based on the monopoly setting. This indicates that indirect taxes policies which aim at persuading and dissuading certain kinds of industry to locate or from locating in its region should receive carefully scrutiny, and there is a need for future research in this area.

Acknowledgements. I would like to thank an anonymous referee for many thoughtful and stimulating comments. Any remaining errors are mine.

\section{References}

Besley, T. (1989) Commodity taxation and imperfect competition: a note on the effect of entry, Journal of Public Economics, 40, 359-367.

Chan, H. T. and Shieh, Y. N. (1997) The effects of sales taxes on the location decision of the firm, RISEC: International Review of Economics and Business, 44, 535-548.

Chen, M. C. and Shieh, Y. N. (2011) Specific commodity taxes, output and location decision under free entry oligopoly, Annals of Regional Science, 47, 25-36.

Hanoch, G. (1975) The elasticity of scale and the shape of average costs, American Economic Review, 65, 492-497.

Hurter, A.P. and Martinich, J.S. (1989) Facility location and the theory of production, Kluwer Academic: Boston.

Hwang, H. and Mai, C.C. (1987) Business taxation and industrial location, RISEC: International Review of Economics and Business, 34, 241-248.

Hwang, H. and Mai, C.C. (1999) Optimal export taxes with an endogenous location, Southern Economic Journal, 65, 940-952. 
Hwang, H., Mai, C.C. and Shieh, Y.N. (2007) Production-location decision and free entry oligopoly: a correction, Journal of Urban Economics, 68, 576-579.

Hwang, C-I and Shieh, Y.N. (2007) Factor market oligopsony and the location decision of free entry oligopoly, Economics Bulletin, 18(6), 1-7.

Kusumoto, S.I. (1984) On a foundation of the economic theory of location - Transport distance vs. technological substitution, Journal of Regional Science, 24, 249-270.

Mai, C.C. and Hwang, H. (1992) Production-location decision and free entry oligopoly, Journal of Urban Economics, 31, 52-71.

Mai, C.C. and Hwang, H. (1997) External economies of scale and optimal plant location, Pacific Economic Review, 2, 115-124.

Martinich, J.S. and Hurter, A. P. (1990) Generalized comparative statics for the productionlocation problem, Regional Science and Urban Economics, 20, 276-294.

Moses, L.M. (1958) Location and the theory of production, Quarterly Journal of Economics, 72, 259-272.

Silberberg, E. (1978) The structure of Economics: a mathematical analysis, McGraw-Hill: New York.

Takayama, A. (1993) Analytical methods in Economics, University of Michigan Press: Ann Arbor.

Tanaka, Y. (1993) On the effects of commodity tax under free entry, Keio Economic Studies, 30, 43-52. 